\title{
Anizometropik Ambliyopi Olgularında Retina Sinir Lifi Tabakası, Maküla Kalınlığı ve Gangliyon Hücre Kompleksinin Değerlendirilmesi
}

\author{
Evaluation of Retinal Nerve Fiber Layer, Macular Thickness and Ganglion \\ Cell Complex in Cases with Anisometropic Amblyopia \\ Turgay Uçak ${ }^{1}$, Nurdan Gamze Taşlı ${ }^{1}$, Erdinç Bozkurt ${ }^{2}$, Erel İçel ${ }^{1}$, Yücel Karakurt ${ }^{1}$, \\ Sümeyye Burcu Ağcayazı1, Mahmut Atum ${ }^{3}$ \\ ${ }^{1}$ Erzincan Binali Yildırım Üniversitesi Tip Fakültesi, Göz Kliniği, Erzincan, Türkiye \\ ${ }^{2}$ Kafkas Üniversitesi Tip Fakültesi, Göz Kliniği, Kars, Türkiye \\ ${ }^{3}$ Sakarya Üniversitesi Tip Fakültesi, Göz Kliniği, Sakarya, Türkiye
}

Yazısma Adresi / Correspondence:
Mahmut Atum
Sakarya Üniversitesi Eğitim ve Araştırma Hastanesi Korucuk Kampüsü, Adapazarı, Sakarya
T: +90 5558096275 E-mail: : mahmutatum@gmail.com
Geliş Tarihi / Received : 05.02.2019 Kabul Tarihi / Accepted : 30.07.2019
Orcid :
Turgay Ucak https://orcid.org/ 0000-0002-4977-4942
Nurdan Gamze Tasli https://orcid.org/ 0000-0001-8587-3430
Erdinç Bozkurt https://orcid.org/ 0000-0002-5570-799X
Erel Icel https://orcid.org/ 0000-0001-7150-5581
Yücel Karakurt https://orcid.org/ 0000-0001-8104-3819
Sümeyye Burcu Ağcayazı https://orcid.org/0000-0003-4673-9233
Mahmut Atum https://orcid.org/0000-0001-8230-8137

$\ddot{0} z$

Amaç Anizometropiye bağlı tek taraflı ambliyopisi bulunan olguların retina sinir lifi tabakası (RSLT), maküla kalınlŏı (MK) ve gangliyon hücre kompleksinin (GHK) optik koherens tomografi (OKT) cihazı ile değerlendirilip, sonuçların sağlam göz ve kontrol grubuyla karşllaştrrılması.. ( Sakarya Tip Dergisi 2019, 9(3):420-425)

Gereç ve Calıșmaya tek gözde anizometropik ambliyopi tespit edilen 89 hastanın 89 ambliyop gözü, kontrol grubu olarakta hasta grubunun 89 sağlam gözü ve 31 sağlıklı kișinin Yöntemler 62 gözü çalışmaya dahil edildi. Tüm olguların detaylı oftalmolojik muayenesinin ardından OKT cihazı ile RSLT, MK ve GHK değerleri ölçülerek istatistiksel olarak karşılaștırıldı, $\mathrm{p}<0,05$ değeri istatistiksel olarak anlamlı kabul edildi.

Bulgular Çalışmaya dahil edilen katılımcıların yaş ortalamaları ambliyopi hasta grubunda $13.19 \pm 6.28$ yıl, kontrol grubunda ise $13.50 \pm 6.50$ yıl idi. MK analizlerine bakıldığında gruplar arasında anlamlı farklılık tespit edilmedi. Olguların ortalama RSLT değerleri arasında gruplar istatistiksel olarak anlamlı farklllk saptanamamısken; superior ve inferior kadran kalınlığı ambliyop gözlerde kontrol grubuna göre anlamlı olarak yüksek bulundu (sırasılyla; p=0,045, p=0,026). GHK değerlendirmesinde üst kadran kontrol grubunda hasta grubuna göre anlamlı olarak daha inceydi $(\mathrm{p}=0,026)$.

Sonuç MK değerinde ambliyopi olguları ile kontrol grubu arasında anlamlı fark bulunmazken, RSLT’de üst ve alt kadran ile GHK üst kadran kalınlıkları hasta grubunda kontrol grubuna göre istatiksel olarak anlamlı yüksek bulunmuştur.

Anahtar ambliyopi; optik koherens tomografi; retina sinir lifi tabakasi; gangliyon hücre kompleksi

Kelimeler

Abstract

Objective To determine nerve fiber layer (RNFL), macular thickness (MT) and ganglion cell complex (GCC) in eyes of children with anisometropic amblyopia, their fellow eyes and eyes of age-matched controls.( Sakarya Med J 2019, 9(3):420-425 ).

In this study, 89 eyes of 89 patients with amblyopia, 89 eyes without amblyopia, and 62 eyes of 31 normal subjects were included. After detailed ophthalmological examination, RNFL, MT and GCC measurements were performed with OCT and compared among the three groups, $p<0,05$ was taken to be significant.

Results The mean age of the participants was $13.19 \pm 6.28$ years in amblyopia patients; the control group was $13.50 \pm 6.50$ years. MT analysis showed no significant difference between the groups. The mean RNFL was evaluated for all three groups, no statistically significant difference was found. Superior and inferior quadrant thickness were significantly higher in amblyopic eyes than the control group (respectively; $p=0,045, p=0,026$ ). In the GCC evaluation, the superior quadrant was significantly thinner in the control group

Conclusion There was no significant difference between amblyopia cases and control group in macular thickness and the RNFL upper and lower quadrant and GCC upper quadrant thickness were found to be statistically significantly higher in the patient group compared to the control group.

Keywords amblyopia; optical coherence tomography; retinal nerve fiber layer; ganglion cell complex 


\section{GIIRIŞ}

Ambliyopi, oftalmik olarak görülebilen patolojik değişiklikler olmaksızın görme keskinliğinde azalma ile karakterize görsel sistemin gelişimsel bir bozukluğudur. ${ }^{1} \mathrm{Bu}$ durum genel popülasyonun yaklaşık \% 2-5'inde görülür. ${ }^{2}$ Strabismus, anizometropi, yüksek refraktif kusur, görsel deprivasyon gibi çeşitli nedenlere bağlı olarak gelişebilir. ${ }^{3}$ Anizometropi iki göz arasında 0,5-2 dioptri kırma kusurunun bulunduğu durumu ifade eder. Anizometropik ambliyopide, fiksasyon noktasından çıkan odaklanmış ve odaklanmamış görüntüler göz fovasında bulanık bir görüntü oluşturur ve üst üste gelen net ve bulanık görüntülerin bir sonucu olarak kırma kusuru düzeltilmemiş gözde foveanın inhibisyonuna ve o gözde zayıf görmeye neden olur. $^{4}$

Patofizyolojisi kesin olarak bilinmemekle birlikte ambliyopi olan gözlerde lateral genikulat nukleustaki (LGN) atrofik değişikliklerin yanı sıra görsel korteksteki değişiklikler primatlar ve insanlar üzerinde yapılan histolojik çalışmalarda gösterilmiştir. ${ }^{5,6}$ Retinada ise ambliyopiye sekonder değişikliklerin olup olmadığı konusunda farklı görüşler vardır. Yen ve ark. ambliyopinin postnatal dönemde retina gangliyon hücrelerinin normal gelişim sürecini bozduğunu ve bunu sonucunda retina sinir lifi tabakasında (RSLT) yeterli incelme olmadığını öne sürmüştür. ${ }^{7}$ Retina katlarını hızlı ve non-invaziv olarak değerlendirebilen bir yöntem olan optik koherens tomografi (OKT) ile RSLT, ganglion hücre kompleksi (GHK) ve makula kalınlığını (MK) sayısal olarak ifade edebilmek mümkündür.

Yaptığımız bu çalışmada, tek taraflı anizometropik ambliyopisi bulunan hastaların ambliyop gözleri ile sağlam gözlerinin MK, GHK ve RSLT sonuçlarını kendi aralarında ve kontrol grubuyla kıyaslayarak değerlendirdik.

\section{GEREÇ ve YÖNTEMLER}

Vaka-kontrol çalışmamıza Ocak 2017 ve Ekim 2018 tarihleri arasında Erzincan Üniversitesi Mengücek Gazi Eğitim ve Araştırma Hastanesi Göz Hastalıkları polikliniğine baş- vuran ve tek gözde ambliyopi tespit edilen 89 hastanın 89 ambliyop gözü, aynı hastaların 89 sağlam gözü ve her iki gözü tam gören 31 kişinin 62 gözü kontrol grubu olarak dahil edildi. Dünya Tıp Birliği Helsinki bildirgesine sadık kalınarak çalışmaya alınan tüm hastalara ve çocukların anne-babasına bilgi verilip yazılı onamı alındı ve etik komite onayı alındı. (16.11.2016-9/11) Snellen eşeline göre görme keskinliği bir gözünde tam; diğer gözünde ise en az 2 sıra ve daha az görme keskinliğine sahip olan olgular ambliyopi olarak değerlendirildi. Geçirilmiş göz cerrahisi, glokom, nistagmus, retinopati, optik disk anomalisi, nörolojik hastalık öyküsü olan ve OKT muayenesini engelleyebilecek optik ortam opasiteleri (korneal lökom, katarakt, vitreus hemorajisi) bulunan olgular çalışma dışı bırakıldı. Göz muayene bulgularının tümü normal olanlar kontrol grubunu oluşturdu.

Tüm olgulara ayrıntılı oftalmolojik muayene yapıldı. Otorefraktometre ile refraksiyon ölçümü sonrası sikloplejik etki olmadan $6 \mathrm{~m}$ uzaklıktan Snellen eşeli ile en iyi düzeltilmiş görme keskinliği (EİGGK) elde edildi. Tüm olgulara şaşılık muayenesi, göz içi basınç ölçümü, biyomikroskop ile ön segment muayenesi ve dilate fundus muayenesi yapıldı. İki göz arasında 2 Diyoptri (D) sferik eşdeğerden fazla refraksiyon farkı anizometropi olarak kabul edildi.

OKT ölçümleri RS-3000 OCT Retina Scan (Nidek Inc., CA, USA) cihazı ile tek hekim tarafından yapıldı. RSLT 4 kadrandan (temporal, superior, nazal ve inferior) ve bunların ortalaması olarak ölçüldü ve kaydedildi. Makulanın topografik kalınlık haritası $1 \mathrm{~mm}$ çaplı fovea alanı, $3 \mathrm{~mm}$ çaplı parafoveal alan (temporal, superior, nasal, inferior kadranlar), $6 \mathrm{~mm}$ çaplı perifoveal alan (temporal, superior, nasal, inferior kadranlar) şeklinde ETDRS'nin (Erken Tedavi Diyabetik Retinopati Çalışması) tanımladığg 9 zon haritası ile değerlendirildi. ${ }^{8}$ Sonuçlar tüm alanlara karşılık gelen diğer gözle karşılaştırıldı.

Tüm değerler SPSS 21.0 programı ile analiz edildi. Normal dağılım gösteren ölçümlerin analizinde One way ANOVA 
testi kullanıldı. Normal dağılım göstermeyen gruplar non parametrik Kruskal-Wallis testi kullanılarak değerlendirildi. Sonuçlar \%95'lik güven aralığında değerlendirildi, $\mathrm{p}<0,05$ olan değerler istatiksel olarak anlamlı kabul edildi.

\section{BULGULAR}

Çalışmaya 89 hastanın 89 ambliyop gözü (Grup I) ve 89 sağlam (Grup II) gözü; ve sağlıklı kişilerden oluşan kontrol grubu (Grup III) olarak da 31 hastanın 62 gözü dahil edildi. Dahil edilen katılımcıların cinsiyet dağılımları değerlendirildiğinde ambliyopi hastalarının $(n=89) 45$ 'i kadın (\%50,60), 44'ü erkek $(\% 49,40)$; kontrol grubunun ise (n=31) 18’i kadın $(\% 58,10), 13$ ü $(\% 41,90)$ erkekti. Cinsiyet dağılımı açısından katılımcılar arasında anlamlı bir fark yoktu $(\mathrm{p}=0,942)$.

Çalışmaya dahil edilen katılımcıların yaş dağılımları ambliyopi grubunda ortalama $13.19 \pm 6.28$ yll; kontrol grubunda ise $13.50 \pm 6.50$ yıl idi. Bu değerler incelendiğinde her iki grup arasında istatistiksel olarak anlamlı fark mevcut değildi $(p=0,949)$.

Olguların ortalama EIDGK Grup I'de 0.55 \pm 0.20 ; Grup II'de $0.95 \pm 0.10$ ve Grup III'te $0.96 \pm 0.10$ idi. Grup I'de EİDGK diğer gruplara göre istatiksel olarak anlamlı oranda düşük bulundu. $(\mathrm{p}<0,001)$.

Çalışmaya dahil edilen tüm katılımcıların göz içi basıncı, sferik ekivalan, aksiyel uzunluk değerleri tablo 1'de sunulmuştur. Buna göre göz içi basıncı ve aksiyel uzunluk değerlerine bakıldığında gruplar arasında istatistiksel olarak anlamlı fark yoktu (sırasıly $\mathrm{p}=0,539, \mathrm{p}=0,582$ ). Sferik ekivalan ölçümleri değerlendirildiğinde; Grup I ve Grup II ile Grup I ve Grup III arasındaki fark istatistiksel olarak anlamliyd $(\mathrm{p}<0,001, \mathrm{p}<0,001)$.

MK analizlerine bakıldığında gruplar arasında anlamlı farklılık tespit edilmedi (Tablo 2). Olguların ortalama

\begin{tabular}{|l|c|c|c|c|c|c|}
\hline \multicolumn{7}{|c|}{ Tablo 1. Hasta ve kontrol grubunun yaş, görme keskinliği, göz içi basıncı, sferik ekivalan ve aksiyel uzunluk değerlerinin karşılaştırılması } \\
\hline & Grup I & Grup II & Grup III & $\mathrm{p}$ (Grup I-Grup II) & $\mathrm{p}$ (Grup I-Grup III) & $\mathrm{p}$ (Grup II-Grup III) \\
\hline Yaş (yıl) & $13.19 \pm 6.28$ & $13.19 \pm 6.28$ & $13.5 \pm 6.50$ & 0,949 & 0,949 \\
\hline $\begin{array}{l}\text { Görme keskinliği } \\
\text { (Snellen) }\end{array}$ & $0.55 \pm 0.20$ & $0.95 \pm 0.10$ & $0.96 \pm 0.10$ & $\mathrm{p}<0,001$ & $\mathrm{p}<0,001$ \\
\hline Göz içi basınc1 (mm Hg) & $13.40 \pm 1.70$ & $13.20 \pm 1.70$ & $13.01 \pm 20$ & 0,539 & 0,642 \\
\hline Sferik Ekivalan (D) & $+3.50 \pm 1.60$ & $+1.30 \pm 1.60$ & $+1.01 \pm 1.20$ & $\mathrm{p}<0,001$ & 0,275 \\
\hline Aksiyel Uzunluk (mm) & $22.82 \pm 1.08$ & $23.10 \pm 0.92$ & $23.22 \pm 1.13$ & 0,582 & 0,833 \\
\hline Veriler ortalama \pm standart sapma olarak verilmiștir. & & 0,001 \\
\hline
\end{tabular}

\begin{tabular}{|c|c|c|c|c|c|c|}
\hline & Grup I & Grup II & Grup III & p (Grup I-Grup II) & p (Grup I-Grup III) & p (Grup II-Grup III) \\
\hline $\operatorname{SMK}(\mu \mathrm{m})$ & $264.83 \pm 33.27$ & $263.49 \pm 26.02$ & $255.50 \pm 21.74$ & 0,946 & 0,116 & 0,204 \\
\hline \multicolumn{7}{|c|}{ Makula İç Kısım } \\
\hline Superior & $338.78 \pm 34.79$ & $342.57 \pm 18.51$ & $336.78 \pm 13.68$ & 0,574 & 0,882 & 0,353 \\
\hline Nasal & $338.83 \pm 20.49$ & $337.22 \pm 15.91$ & $333.83 \pm 18.22$ & 0,830 & 0,231 & 0,508 \\
\hline İnferior & $325,65 \pm 27.32$ & $320.43 \pm 57.55$ & $321.75 \pm 30.48$ & 0,685 & 0,841 & 0,980 \\
\hline Temporal & $317.70 \pm 23.58$ & $320.79 \pm 18.48$ & $315.61 \pm 22.59$ & 0,605 & 0,827 & 0,315 \\
\hline \multicolumn{7}{|c|}{ Makula Dıș Kısım } \\
\hline Superior & $304.95 \pm 17.29$ & $303.64 \pm 15.46$ & $302.06 \pm 12.59$ & 0,839 & 0,499 & 0,813 \\
\hline Nasal & $320 \pm 17.72$ & $319.46 \pm 14.47$ & $315.24 \pm 14.45$ & 0,972 & 0,163 & 0,240 \\
\hline İnferior & $306.06 \pm 19.19$ & $302.70 \pm 18.75$ & $302.53 \pm 17.15$ & 0,449 & 0,482 & 0,998 \\
\hline Temporal & $291.39 \pm 33.54$ & $292.89 \pm 18.77$ & $283.95 \pm 24.67$ & 0,925 & 0,217 & 0,112 \\
\hline
\end{tabular}


RSLK her üç grup için değerlendirildiğinde istatistiksel olarak anlamlı farklılık saptanamamışken; superior ve inferior kadran kalınlığı ambliyop gözlerde kontrol grubuna göre anlamlı olarak yüksek bulundu (sırasıyla; $\mathrm{p}=0,045$, $\mathrm{p}=0,026)$. Diğer kadranlarda belirgin farklılık mevcut değildi. GHK değerlendirmesinde üst kadran kontrol grubunda belirgin olarak daha inceydi $(\mathrm{p}=0,026)$ (Tablo 3).

\begin{tabular}{|l|c|c|c|c|c|c|}
\hline Tablo 3: Grup I,II ve III'e ait retina sinir lifi tabakası ve gangliyon hücre kompleksi sonuçlarının karşılaştırılması \\
\hline RSLT & Grup I & Grup II & Grup III & p (Grup I-Grup II) & p (Grup I-Grup III) & p (Grup II-Grup III) \\
\hline Ortalama & $103.31 \pm 9.74$ & $101.78 \pm 10.28$ & $101.27 \pm 12.51$ & 0,618 & 0,525 & 0,960 \\
\hline Superior & $130.82 \pm 25.01$ & $130.05 \pm 21.47$ & $121.88 \pm 22.76$ & 0,974 & 0,045 & 0,086 \\
\hline Nasal & $82.34 \pm 18.48$ & $80.59 \pm 18.80$ & $78.55 \pm 25.30$ & 0,839 & 0,513 & 0,824 \\
\hline İnferior & $137.38 \pm 21.52$ & $133.48 \pm 23.42$ & $126.66 \pm 30.49$ & 0,547 & 0,026 & 0,222 \\
\hline Temporal & $59.92 \pm 13.82$ & $63.89 \pm 11.85$ & $63.29 \pm 10.21$ & 0,088 & 0,232 & 0,953 \\
\hline Temporal & $317.70 \pm 23.58$ & $320.79 \pm 18.48$ & $315.61 \pm 22.59$ & 0,605 & 0,827 & 0,315 \\
\hline GHK & $103.87 \pm 8.85$ & $104.20 \pm 8.81$ & $100.67 \pm 7.00$ & 0,964 & 0,058 & 0,032 \\
\hline Superior & $102.55 \pm 13.72$ & $102.94 \pm 13.10$ & $99.69 \pm 11.12$ & 0,977 & 0,373 & 0,280 \\
\hline İnferior
\end{tabular}

\section{TARTIŞMA}

Organik bir patoloji olmaksızın, tek veya bilateral olarak, EIDGK düşük olduğu durumlar ambliyopi olarak tanımlanmaktadır. Ambliyopi, görsel ileti yolunun gelişim sürecinde meydana gelmekte ve toplumun \%2-6'sında görülmektedir. ${ }^{9}$ Başlıca nedenleri strabismus, anizometropi, görsel deprivasyon ve düzeltilmemiş refraksiyon kusurlaridir. ${ }^{10}$

Ganglion hücre aksonlarının oluşturduğu RSLT, optik sinir boyunca lateral genikulat cisme uzanmakta, ambliyop olgularda, postnatal dönemde retina ganglion hücrelerinin normal gelişim sürecinin bozulduğu ve buna bağlı olarak maküla ve retina sinir lifi tabakasının etkilenebileceği düşünülmektedir.7 Von Noorden, uzun süre kapak sütürasyonu ile deneysel olarak oluşturduğu ambliyop gözlerin LGN'lerinde atrofi meydana geldiğini, parafoveal retina gangliyon hücre boyutu ve yoğunluğunda ise azalma olduğunu göstermiş, azalmanın deprivasyon sonucunda oluşan kortikal değişimlere ikincil geliştiği yorumunu yapmıştır. ${ }^{6}$ Diğer bir hayvan çalışmasında deneysel ambliyopi oluşturulan hayvanların ganglion hücre sitoplazması ve internal pleksiform tabakada incelme, optik sinir boyutlarında kısalma olduğu görülmüştür. ${ }^{11}$ Yazıcı ve ark.'nın ratlar üzerinde yaptığ 1 çalışmada diğer çalışmaları destekler nitelikte olup, baskın gözdeki akson sayısının, deprivasyon uygulanan gözlere göre belirgin olarak fazla olduğunu tesbit etmişler. ${ }^{12}$ Literatürde bu çalışmaların aksini iddia eden çalışmalar da mevcuttur. Park ve ark. 40 strabismik ve anisometropik ambliyopik hasta ile 40 tane strabismik ve anisometropik non-ambliyopik hastanın ortalama RSLT ve GHK kalınlığını kıyasladığı çalışmada her iki parametrenin de ambliyopik olan grupta daha kalın olduğunu saptamışlardır. ${ }^{13}$ Cleland ve ark. ise bu düşüncelerin aksine yaptığı deneysel çalışmalarda ambliyopik gözlerdeki retina gangliyon hücrelerinde herhangi bir azalma olmadığını bildirmişlerdir. ${ }^{14}$ Bizim yaptığımız bu çalışma da Cleland ve ark. destekler nitelikte olup, kontrol grubunda üst kadranda GHK'inin daha ince olduğunu saptadık, alt kadranda gruplar arası anlamlı bir farklılık izlemedik.

Fırat ve ark. 36 ambliyopik hasta üzerinde yaptığı çalışmada, santral makula kalınlığg (SMK), makula volümü (MV) ve GHK kalınlığını değerlendirmiş olup, sağlam ile ambli- 
yop gözler arasında anlamlı bir fark bulmamışlardır. ${ }^{15}$ Çelik ve ark. yaptığı bir diğer çalışmada MV, RSLT ve GHK kalınlıkları açısından, ambliyop ve normal gözler arasında, istatistiksel olarak anlamlı bir fark saptanmamıştır. ${ }^{16}$ Kee ve ark. tek gözü ambliyop olan 26 hastanın 52 gözü üzerinde yaptıkları çalışmada sağlam göz ile ambliyop göz arasında RSLT kalınlığı açısından anlamlı bir fark bulmamıştır.17 Repka ve ark. yaşları 7 ila 12 arasında değişen 37 ambliyop hastanın gözünde yaptıkları çalışmada RSLT kalınlığı açısından sağlam göz ile ambliyop göz arasında anlamlı bir fark bulmamıştır. ${ }^{18}$ Maggadah ve ark. 54 strabismik ve anisometropik hastada yaptığı çalışmada her ne kadar strabismik ambliyopların superior ve nasal kadranlarında RSLT kalınlığında azalma görseler de bu değişiklikler sağlam göze göre istatistiksel olarak anlamlı değil idi. ${ }^{19}$ Bizim çalışmamızda da ortalama RSLT kalınlığının gruplar arasında anlamlı bir farklılık oluşturmadı̆̆ını izledik.

4118 olgunun dahil olduğu bir çalışmada, ambliyopik gözle normal göz arasında peripapiller RSLT kalınlığı açısindan anlamlı bir fark görülmezken, ambliyopik gözde makuler kalınlığın daha fazla olduğunu belirtmişlerdir. ${ }^{20}$ Benzer şekilde Al Haddad ve ark. da yaptıkları çalışmalarında ambliyop gözlerde SMK'yı anlamlı şekilde $6.8 \mu$ daha fazla bulmuşlardır. ${ }^{21}$ Yen ve ark. 38 gözün dahil olduğu bir çalışmada ambliyopik gözlerdeki strabismusa bağlı ambliyopilerin RSLT kalınlığını sağlam gözlere göre benzer, anizometropik gözlerin RSLT kalınlığının ise sağlam gözlere göre $10 \mu \mathrm{m}$ fazla olduğunu, bu durumun istatistiksel olarak anlamlı bulunduğunu belirtmişlerdir. ${ }^{7}$ Yoon ve ark. tek taraflı ambliyopisi olan 31 hasta üzerinde yaptıkları çalışmada ambliyopik gözlerdeki RSLT kalınlığının (115 $\mu \mathrm{m})$ sağlam gözlerdeki RSLT kalınlığından (109 $\mu \mathrm{m})$ anlamlı düzeyde yüksek, SMK’nın ise benzer düzeyde olduğunu bulmuşlardır. ${ }^{22}$ Biz de çalışmamızda RSLT kalınlığı açısından ambliyop hastaların her iki göz süperior ve inferior kadranlarının kontrol grubuna göre anlamlı düzeyde yüksek olduğunu, SMK'ında ise gruplar arasında anlamlı bir farklılık olmadığını saptadık.
Sonuç olarak, bu çalışmada ambliyopi olgularında RSLK üst ve alt kadranda, GHK üst kadranda kontrol grubuna göre anlamlı kalınlık saptandı. Ambliyopide temel patoloji görsel korteks ile ilişkili görünse de retinada da sekonder değişiklikler bulunabilir. Daha çok olgu içeren geniş serili çalışmalar ambliyopide bulunan retina ve optik sinirdeki değişikliklerin değerlendirilmesine açıklık getirecektir. 
Sakarya Tip Dergisi 2019;9(3):420-425

UÇAK ve Ark., Ambliyopi Olgularında RSLT, MK ve GHK Değerlendirilmesi

\section{Kaynaklar}

1. Holmes JM, Clarke MP. Amblyopia. Lancet 2006;367(9519):1343-51.

2. Brémond-Gignac D, Copin H, Lapillonne A, Milazzo S. Visual development in infants: physiological and pathological mechanisms. Curr Opin Ophthalmol 2011;22:1-8.

3. Chen W, Chen J, Huang J, Xu J, Zhang F, Lu F. Comparison of Macular and Retinal Nerve Fiber Layer Thickness in Untreated and Treated Binocular Amblyopia. Curr Eye Res 2013;38(12):1248-54.

4. DeSantis D. Amblyopia. Pediatr Clin North Am 2014;61(3):505-18.

5. Campos E. Amblyopia. Surv Ophthalmol 1995;40(1):23-39.

6. von Noorden GK. Histological studies of the visual system in monkeys with experimental amblyopia. Invest Ophthalmol 1973;12(10):727-38.

7. Yen $M-Y$, Cheng $C-Y$, Wang A-G. Retinal nerve fiber layer thickness in unilateral amblyopia. Invest Ophthalmol Vis Sci 2004;45(7):2224-30.

8. Photocoagulation For Diabetic Macular Edema: Early Treatment Diabetic Retinopathy Study Report Number 1 Early Treatment Diabetic Retinopathy Study Research Group. Arch Ophthalmol 1985;103(12):1796-806

9. Szigeti A, Tátrai E, Szamosi A, et al. A morphological study of retinal changes in unilateral amblyopia using optical coherence tomography image segmentation. PLoS One 2014;9(2):e88363. doi: 10.1371/journal.pone.0088363

10. Shimko JF. Binocular Vision and Ocular Motility Theory and Management of Strabismus. Am Orthopt J 2001;51(1):161-2.

11. Chow KL. Failure to demonstrate changes in the visual system of monkeys kept in darkness or in colored lights. J Comp Neurol 1955;102(3):597-606.

12. Yazici AT, Malkoç I, Altunkaynak BZ, et al. Number of axons in the right and left optic nerves of right-pawed and left-pawed rats: a stereologic study. Anal Quant Cytol Histol 2009;31(3):177-83.
13. Park JM, Choi YJ, Kim DH. The Analysis of Peripapillary RNFL, Macula and Macular Ganglion Cell Layer Thickness in Patients with Monocular Amblyopia Using SD-OCT. J Korean Ophthalmol Soc 2016;57(1):98-105.

14. Cleland BG, Crewther DP, Crewther SG, Mitchell DE. Normality of spatial resolution of retinal ganglion cells in cats with strabismic amblyopia. J Physiol 1982;326:235-49.

15. Firat PG, Ozsoy E, Demirel S, Cumurcu T, Gunduz A. Evaluation of peripapillary retinal nerve fiber layer, macula and ganglion cell thickness in amblyopia using spectral optical coherence tomography. Int J Ophthalmol 2013;6(1):90-94

16. Çelik E, Dogan E, Çakir B, Alisan S, Aksoy N, Alagoz G. Ambliyopide Fotoreseptör Tabaka Bütünlügü, Retina Sinir Lifi Tabakasi, Merkezi Maküla ve Ganglion Hücre Kompleksi Kalinliginin Degerlendirilmesi. Retina-Vitreus 2015;23(2):149-53.

17. Kee S-Y, Lee S-Y, Lee $Y$-C. Thicknesses of the fovea and retinal nerve fiber layer in amblyopic and normal eyes in children. Korean J Ophthalmol 2006;20(3):177-81.

18. Repka MX, Kraker RT, Tamkins SM, et al. Retinal Nerve Fiber Layer Thickness in Amblyopic Eyes. Am J Ophthalmol 2009;148(1):143-7.

19. Soltani Moghaddam R, Medghalchi A, Alizadeh Y. Survey of Nerve Fiber Layer Thickness in Anisometropic and Strabismic Amblyopia. Acta Med Iran 2017;55(1):24-8.

20. Huynh SC, Samarawickrama C, Wang XY, et al. Macular and nerve fiber layer thickness in amblyopia: the Sydney Childhood Eye Study. Ophthalmology 2009;116(9):1604-9.

21. Al-Haddad CE, El Mollayess GM, Mahfoud ZR, Jaafar DF, Bashshur ZF. Macular ultrastructural features in amblyopia using high-definition optical coherence tomography. $\mathrm{Br} \mathrm{J}$ Ophthalmol 2013;97(3):318-22.

22. Yoon SW, Park WH, Baek S-H, Kong SM. Thicknesses of Macular Retinal Layer and Peripapillary Retinal Nerve Fiber Layer in Patients with Hyperopic Anisometropic Amblyopia. Korean J Ophthalmol 2005;19(1):62. 